\title{
Therapeutic potential of human amniotic membrane-derived mesenchymal stem cells in APP transgenic mice
}

\author{
HONGLIANG JIAO $^{1 *}, \mathrm{KE} \mathrm{SHI}^{2 *}$, WEIJIE ZHANG $^{3 *}$, LIANG YANG $^{4}$, LU YANG $^{5}$, FANGXIA GUAN $^{5}$ and BO YANG ${ }^{1}$ \\ ${ }^{1}$ Department of Neurosurgery, The First Affiliated Hospital, Zhengzhou University, Henan 450052; \\ ${ }^{2}$ Department of Biochemistry and Molecular Biology, Henan Medical College, Henan 451191; ${ }^{3}$ Department of Oncology, \\ The First Affiliated Hospital, Zhengzhou University, Henan 450052; ${ }^{4}$ Department of Pathogen Biology and Immunology, \\ Henan Medical College, Henan 451191; ${ }^{5}$ Department of Bioengineering, \\ Zhengzhou University, Zhengzhou, Henan 450001, P.R. China
}

Received May 19, 2015; Accepted June 27, 2016

DOI: $10.3892 / \mathrm{ol} .2016 .4857$

\begin{abstract}
Growing evidence indicates that the presence of extensive oxidative stress plays an essential role in the initiation and progression of Alzheimer's disease (AD). Amyloid- $\beta$ $(\mathrm{A} \beta)$ aggregation is involved in the elevation of oxidative stress, contributing to mitochondrial dysfunction and lipid peroxidation. In the present study, human placenta amniotic membrane-derived mesenchymal stem cells (hAMMSCs) were intravenously injected into C57BL/6J-APP transgenic mice. hAMMSCs significantly ameliorated spatial learning and memory function, and were associated with a decreased amount of amyloid plaques of the brain. The correlation of oxidative stress with $\mathrm{A} \beta$ levels was lower in the hAMMSCs-injected group than in the phosphate-buffered saline (PBS)-injected group, as indicated by the increased level of antioxidative enzymes and the decreased level of lipid peroxidation product. The glutathione (GSH) level and ratio of GSH to glutathione disulfide were higher in the hAMMSC group than in the PBS group. The superoxide dismutase activity and malonaldehyde level were improved significantly as the level of $A \beta$ decreased, but there was no such trend in the PBS group. As a result, our findings represent evidence that hAMMSC treatment might improve the pathology of $\mathrm{AD}$ and memory function through the regulation of oxidative stress.
\end{abstract}

Correspondence to: Dr Bo Yang, Department of Neurosurgery, The First Affiliated Hospital, Zhengzhou University, 40 Daxue Road, Zhengzhou, Henan 450052, P.R. China

E-mail: yangbozzu@yahoo.com

${ }^{*}$ Contributed equally

Key words: Alzheimer's disease, human placenta amniotic membrane-derived mesenchymal stem cells, transgenic mice, spatial memory function, amyloid- $\beta$ deposition, oxidative stress

\section{Introduction}

Alzheimer's disease (AD) is the most prevalent chronic neurodegenerative disorder, demonstrating widespread degeneration in numerous types of neuron. Individuals with AD exhibit memory loss and severe cognitive decline caused by the formation of amyloid plaques in the brain parenchyma, particularly in the hippocampus and cerebral cortex. The increased accumulation of misfolded amyloid- $\beta$ (A $\beta)$ peptides in the senile plaque core is the main cause of the neurodegenerative action of $\mathrm{AD}$ (1). Thus, preventing the deposition of $\mathrm{A} \beta$ in the brain could be a feasible strategy in the therapy of AD.

Increasing evidence has demonstrated that the presence of extensive oxidative stress plays an essential role in the initiation and progression of AD. On the one hand, the elevated oxidative stress may be induced by $\mathrm{A} \beta$ aggregation resulting in mitochondrial dysfunction and lipid peroxidation $(2,3)$. A $\beta$ treatment has been demonstrated to enhance the hydrogen peroxide and lipid peroxides levels in cell models (4). In addition, oxidative modifications of proteins and lipids were increased in a AbPP/PS1 transgenic mouse model associated with $A \beta$ accumulation $(5,6)$. The soluble $A \beta$ oligomers induced the reactive oxygen species (ROS), causing synaptic impairment and neuronal loss in hippocampal neuronal cells (7). These studies demonstrated that $A \beta$ contributes to increased oxidative stress in AD models. Conversely, a significant number of studies have suggested that oxidative stress is involved in the production of $\mathrm{A} \beta$. It was reported that enhanced oxidative stress caused by defects in the antioxidant defense system notably increased the deposition of A $\beta$ in APP overexpression transgenic mice (8). In addition, the antioxidant supplement ameliorated the brain $A \beta$ plaque burden and cognitive dysfunction (9). Several studies revealed that oxidative stress induced the expression of $\beta$-secretases BACE1 and PS1 and the activity of $\gamma$-secretase, while it decreased the activity of $\alpha$-secretase for A $\beta$ production from APP $(10,11)$. Previously, the Butterfield laboratory reported that protein oxidation and lipid peroxidation were associated with AD brain regions with abundant $A \beta$ but not in $A \beta$-poor cerebellum, indicating that $A \beta$ (1-42)-associated oxidative stress is responsible for the pathogenesis and progression of AD (12). Since 
oxidative stress-mediated toxicity is a key factor contributing to neurodegenerative events, developing efficient antioxidant protection is an attractive strategy for AD therapy.

Current developments in mesenchymal stem cell (MSC) technology have stimulated new therapies for neurodegenerative disorders including AD. Collected evidence indicates that stem cell-based approaches have potential for use in the treatment of neurodegenerative diseases AD (13). MSCs have been demonstrated to play an effective role in neuroprotection through decreasing apoptosis and oxidative stress (14). In stroke-prone spontaneously hypertensive rats, the superoxide, apoptotic cells and by-products of lipid peroxidation were decreased following MSC treatment (15). Human umbilical cord blood-derived MSCs exhibited low antioxidant enzyme activity by decreasing the gene expression levels of ROS scavenging enzymes, including catalase, superoxide dismutase (SOD) and glutathione peroxidase (GPx) (16). MSCs could be employed as an antioxidant to prevent the progression of AD by its antioxidant activity.

Amniotic membrane has the potential for the generation of MSCs due to the convenience of its acquirement from fetal tissue without any ethical conflict and its high efficiency in the production of MSCs. In contrast with other mesenchymal cells, including human bone marrow-derived MSCs and umbilical cord blood-derived MSCs, human amniotic membrane-derived MSCs (hAMMSCs) do not possess the major histocompatibility complex class I molecule and may exhibit immunological tolerance.

However, whether hAMMSCs are capable of ameliorating oxidative stress, which is inextricably linked with several major pathological processes in $\mathrm{AD}$, remains unknown. In the present study, we investigated the effects of intravenous infusions of hAMMSCs in a transgenic mouse model of AD for the first time.

\section{Materials and methods}

Isolation and in vitro culture of hAMMSCs. Human term placentas were collected with informed consent from healthy females following Caesarean section and washed immediately several times with phosphate-buffered saline (PBS) containing $200 \mathrm{U} / \mathrm{ml}$ penicillin and $100 \mu \mathrm{g} / \mathrm{ml}$ streptomycin. The study procedure was approved by the ethics committee of Zhengzhou University, China. The isolation of hAMMSCs was performed according to a previously described method (17). Amniotic membrane was bluntly dissected from the chorion and cut into small pieces. The minced amnion was subjected to $60-\mathrm{min}$ digestion with $0.25 \%$ trypsin (Sigma-Aldrich, Steinheim, Germany) and collagenase I solution $(0.75 \mathrm{mg} / \mathrm{ml})$ in Dulbecco's modified Eagle's medium (DMEM; Sigma-Aldrich) at $37^{\circ} \mathrm{C}$. Following the centrifugation of supernatant at $252 \times \mathrm{g}$ for $10 \mathrm{~min}$, the pellet was suspended in DMEM containing $10 \%$ heat-inactivated fetal bovine serum, $100 \mathrm{U} / \mathrm{ml}$ penicillin, $100 \mu \mathrm{g} / \mathrm{ml}$ streptomycin and $2 \mathrm{mM}$ L-glutamine (Sigma-Aldrich) and was cultured at $37^{\circ} \mathrm{C}$ in $5 \% \mathrm{CO}_{2}$. The harvest cells were analyzed by flow cytometry to confirm stem cell characteristics previously described (18).

Animals and injection of hAMMSCs. The full-length mutant APP cDNA 695 V 717 I gene of humans was transferred into
C57BL/6J mice (C57BL/6J-APP mice) to create a transgenic mouse model of AD (19), which was employed to examine the effect of hAMMSC transplantation. The C57BL/6J-APP mice were obtained from the Institute of Experimental Animals, Chinese Academy of Medical Sciences (Beijing, China). All experimental animals were housed under a 12/12-h dark/light cycle in specific pathogen-free conditions and handled following the provisions and general recommendations of Chinese Experimental Animal Administration legislation.

For intravenous injection, $500 \mu 1$ amounts of cell suspension $\left(\sim 1 \times 10^{6}\right.$ cells $)$ were injected into the tail vein (hAMMSC-injected group). The mice of the control group received an injection of $500 \mu \mathrm{l}$ PBS into the tail vein. Adult C57BL/6J-APP mice (11 months old; $n=10$ per group) were used for the behavioral experiments and for pathological analysis at 3 weeks after transplantation. Wild-type littermate mice ( 11 months old; $n=9$ ) were used as the negative control group.

Tissue preparation and staining. Following anesthetization with chloral hydrate, mice were immediately cardiac-perfused with $0.9 \%$ saline solution followed by $4 \%$ paraformaldehyde in $0.1 \mathrm{M}$ PBS ( $\mathrm{pH} 7.4$ ). Following perfusion, the brains of the mice were excised and postfixed overnight at $4^{\circ} \mathrm{C}$ and mounted on slides. The slides were washed in PBS three times and $80 \%(\mathrm{v} / \mathrm{v})$ methanol, then pretreated with $0.3 \%$ hydrogen peroxide/methanol for $25 \mathrm{~min}$ in order to quench the endogenous peroxidase activity. The sections were blocked with $10 \%$ normal goat serum in PBS for 30 min to prevent nonspecific protein binding, then washed and incubated with anti-A $\beta$ monoclonal antibody (6E10, 1:100; Covance Inc., Princeton, NJ, USA) in 3\% bovine serum albumin (BSA)/PBS overnight at $4^{\circ} \mathrm{C}$ in a humid chamber. After washing with PBS three times, the sections were incubated with appropriate biotin-conjugated secondary antibody for $1 \mathrm{~h}$, and then horseradish peroxidase-labeled streptavidin was added. The tissues were washed and stained using the diaminobenzidine substrate method and counterstained with hematoxylin.

Behavior test. The modified Morris water maze test was used to assess the spatial memory performance of mice (20). For spatial acquisition tests, mice were placed into a pool and were given $60 \mathrm{sec}$ to find a hidden platform. Mice that failed to find the platform within $60 \mathrm{sec}$ were guided to the platform. Four trials were performed for each mouse every day. In the basic acquisition training, the starting positions were north, east, southeast and northwest, and the platform was placed in the southwest quadrant. After that, the platform was removed and mice were located at a new starting position (northeast) in the maze and allowed to swim for $60 \mathrm{sec}$.

Cell proliferation assay. Following the third passage, hAMMSCs were seeded at 1000 cells $/ \mathrm{cm}^{2}$ in a 6 -well plate (Corning, Inc., Corning, NY, USA). After 4, 7, 10, 14, 17 and 21 days' culture, cells were collected by $0.25 \%$ Trypsin-EDTA solution at $37^{\circ} \mathrm{C}$ for 2 min and counted using a hemocytometer. Trypan blue staining (Sigma-Aldrich) was used to exclude the dead cells. All experiments were carried out in triplicate. 


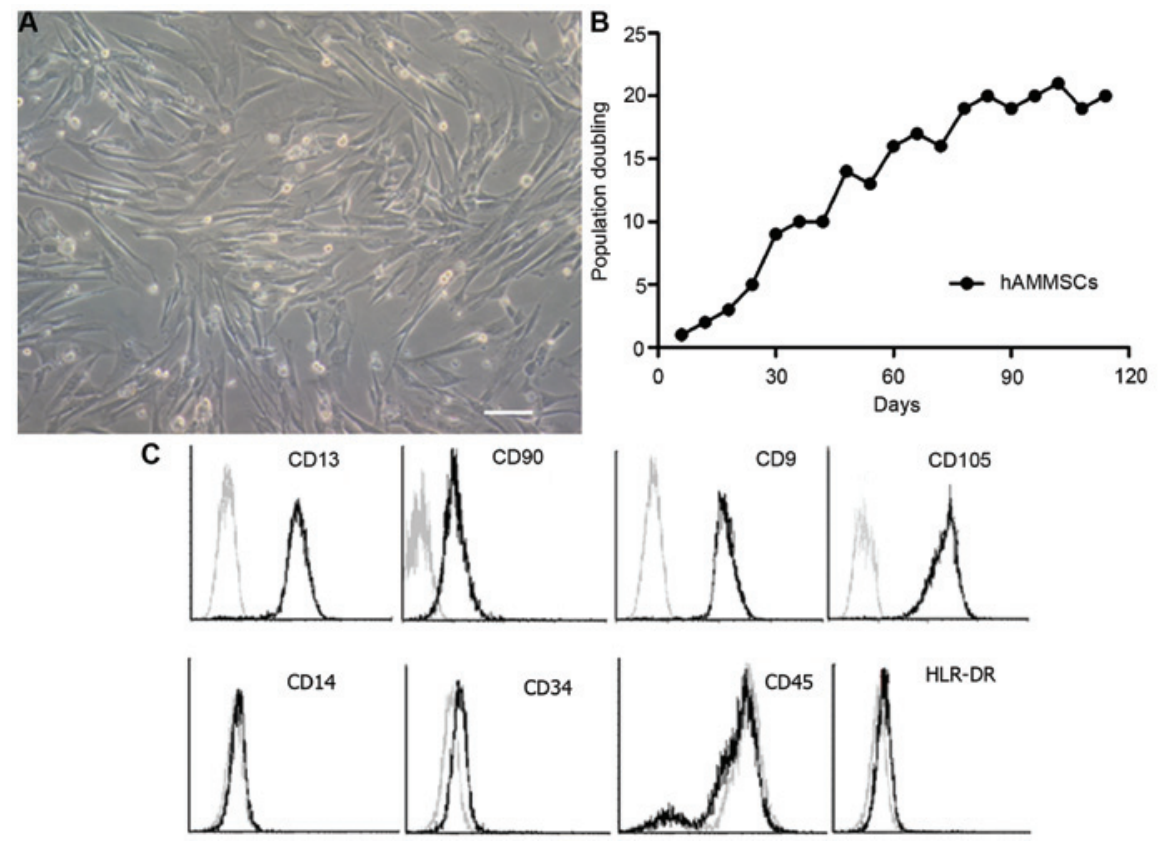

Figure 1. Cellular phenotype and surface adhesion molecule expression of human amniotic membrane-derived mesenchymal stem cells (AMMSCs). (A) Phase contrast microscopic view of AMMSCs (scale bar: $20 \mu \mathrm{m}$ ). (B) Representative growth curves of AMMSCs as a function of time following cell culture. (C) Flow cytometric analysis result of surface adhesion molecules in AMMSCs. AMMSCs were labeled with monoclonal antibodies specific to the indicated molecules. AMMSCs were positive for CD13, CD9, CD90 and CD105, and negative for CD14, CD34, CD45 and HLA-DR.

Measurement of $A \beta 40$ and $A \beta 42$ levels by enzyme-linked immunosorbent assay (ELISA). Following the behavior test, brain samples were isolated from the C57BL/6J-APP transgenic mice and stored at $-80^{\circ} \mathrm{C}$ until use. The $\mathrm{A} \beta 40$ and A $\beta 42$ levels were assayed by ELISA according to a previously described method (21). Briefly, one hemisphere was homogenized in eight volumes of ice-cold guanidine buffer (5.0 M guanidine- $\mathrm{HCl}, 50 \mathrm{mM}$ Tris- $\mathrm{HCl}, \mathrm{pH} 8.0$ ) and incubated at room temperature for $4 \mathrm{~h}$. Ice-cold reaction buffer BSAT-DPBS (Dulbecco phosphate-buffered saline, with 5\% BSA, $0.03 \%$ Tween-20, $0.2 \mathrm{~g} / 1 \mathrm{KCl}, 0.2 \mathrm{~g} / 1 \mathrm{KH}_{2} \mathrm{PO}_{4}, 8.0 \mathrm{~g} / 1$ $\mathrm{NaCl}, 1.150 \mathrm{~g} / 1 \mathrm{Na}_{2} \mathrm{HPO}_{4}, \mathrm{pH}$ 7.4) containing $1 \mathrm{X}$ protease inhibitor cocktail (Invitrogen Life Technologies, Carlsbad, CA, USA) was employed to dilute the homogenate to 1:20. The mixture was centrifugated at $25,200 \mathrm{x} \mathrm{g}$ at $4^{\circ} \mathrm{C}$ for $20 \mathrm{~min}$ and the supernatant was used to quantify the $A \beta 40$ and $A \beta 42$ levels using $A \beta 40$ and $A \beta 42$ ELISA kits (Invitrogen Life Technologies) according to the manufacturer's instructions.

Measurement of antioxidant capacity. Brain homogenates were added to nine volumes of ice-cold $0.9 \%$ saline and centrifugated at $100,710 \mathrm{x} \mathrm{g}$ for $10 \mathrm{~min}$ at $4^{\circ} \mathrm{C}$. The supernatant in the brain homogenate was used to determine the levels of glutathione (GSH) and glutathione disulfide (GSSG) using commercial kits (Beyotime Institute of Biotechnology, Shanghai, China) as per the manufacturer's instructions (22). The optical density was read at $405 \mathrm{~nm}$ on a microplate reader. The activity of SOD and malonaldehyde (MDA) in the brain homogenate was detected using assay kits (Nanjing Jiancheng Bioengineering Institute, Nanjing, China) (23).

Statistical analysis. All data are shown as the means \pm standard error, and were obtained from at least three separate experiments (with the exception of behavioral data). Student's $\mathrm{t}$-test was performed to determine the difference between two groups, and a one-way analysis of variance (ANOVA) test was used to compare one-variable data for more than two groups. The two-way repeated-measures ANOVA was utilized to value the statistical significance for two-variable experiments. $\mathrm{P} \leq 0.05$ was considered to indicate a statistically significant difference.

\section{Results}

Isolation and characterization of hAMMSCs. The morphology of harvested hAMMSCs at passage 4 of culture is shown in Fig. 1A. hAMMSCs exhibited strong viability by MTT assay (Fig. 1B) with $\sim 20$ population doublings, suggesting that amniotic membrane is an abundant source for the generation of mesenchymal cells. In order to estimate the purity of hAMMSC cultures, flow cytometry analysis was used to analyze the immunophenotypic surface profile of the hAMMSCs. Surface marker analysis revealed that hAMMSCs were positive for mesenchymal lineage markers CD13, CD90, CD9 (a nontrophoblast marker) and CD105, and negative for hematopoietic lineage markers CD14, CD34, CD45 and HLR-DR (Fig. 1C).

Transplantation of hAMMSCs attenuates spatial learning and memory function in $A D$ transgenic mice. To investigate the effect of hAMMSC transplantation on the learning and memory of AD transgenic mice, a Morris water maze test was conducted 3 weeks after hAMMSC transplantation. C57BL/6J-APP transgenic mice overexpress the APP695 gene and secrete endogenous $A \beta$, contributing to the deposition of $A \beta$ mainly in the neurons of the cerebral cortex and hippocampus. During the acquisition training phase of the water maze test, the PBS-injected control group exhibited notable learning and memory dysfunction compared with the normal 

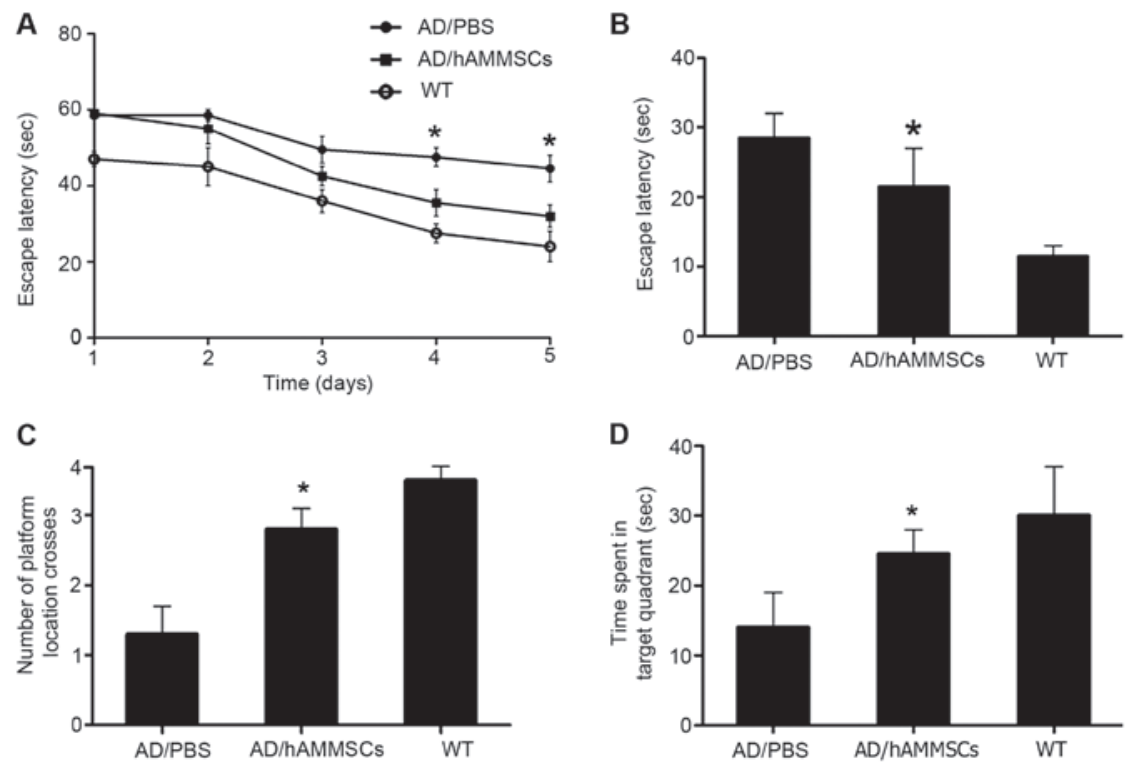

Figure 2. Transplantation of human amniotic membrane-derived mesenchymal stem cells (AMMSCs) attenuates spatial learning and memory function in Alzheimer's disease (AD) transgenic mice. (A) Mice in each group were subjected to the water maze test every day and the escape latency was measured to examine the spatial learning ability of mice. AMMSC transplantation ameliorated spatial memory in the AD mice. A probe test without a platform was performed one day after the last training trial to investigate spatial memory. (B) Effect of AMMSC transplantation on escape latency during the memory trial (C) Number of platform location crossings and (D) time spent in target quadrant during the spatial memory test in the probe trial. "P<0.05 vs. phosphate-buffered saline (PBS)-treated control group. WT, negative control group.

A

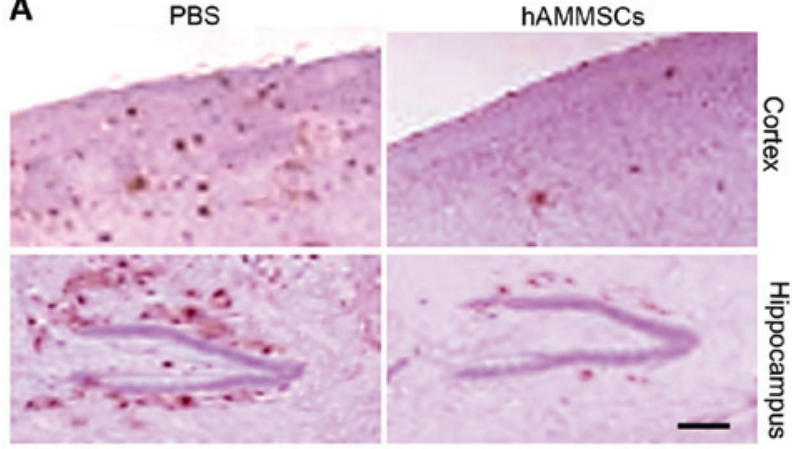

B

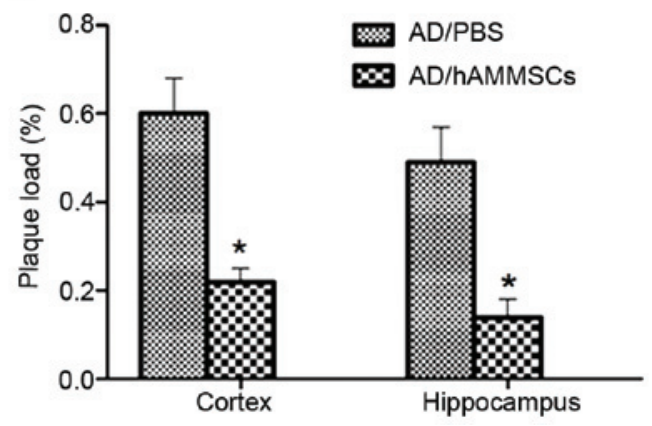

Figure 3. Human amniotic membrane-derived mesenchymal stem cell (AMMSC) treatment attenuates amyloid- $\beta$ (A $\beta$ ) deposition in the brains of Alzheimer's disease (AD) transgenic mice. (A) Plaques of the cerebral cortex and hippocampus were observed by Congo red staining (scale bar: $200 \mu \mathrm{m}$ ). (B) Morphometric analysis was performed to qualify the plaques in the cortex and hippocampus. ${ }^{*} \mathrm{P}<0.05$ vs. phosphate-buffered saline (PBS) group.

control mice, whereas the hAMMSCs-injected group located the hidden platform significantly faster than the PBS-injected control group, and demonstrated no significantly difference from the normal control group, indicating significantly improved learning and memory function (Fig. 2A). Then, we performed a probe test one day after the last training trial to examine the spatial memory. The platform was removed and the time taken to reach the same zone was recorded within $60 \mathrm{sec}$. The PBS-injected control group spent less time in the target quadrant than the hAMMSC group and the normal mice ( $\mathrm{P}<0.01$; Fig. 2B-D), demonstrating that the deficit in spatial memory was rescued by hAMMSC transplantation.

Attenuated A $\beta$ deposition by hAMMSC transplantation. Since $\mathrm{A} \beta$ deposition is the main pathogenic cause of AD inducing cognitive deficits, brain tissue excised from mice following the water maze test was incubated with anti-A $\beta$ 6E10 antibody to observe the changes in A $\beta$ deposition. hAMMSC transplantation notably decreased the $A \beta$ plaques in the cortex and hippocampus of mice compared with the PBS-injected control group (Fig. 3A). Plaque load was qualified by morphometric analysis and is shown as the percentage of the total area demonstrating immunoreactivity of $\mathrm{A} \beta$. The PBS-treated AD mice demonstrated severe $\mathrm{A} \beta$ deposition with plaque levels of $60 \%$ and $49 \%$ in the cortex and hippocampus, whereas the hAMMSC group demonstrated a reduced plaque load of $22 \%$ and $14 \%$ in the cortex and hippocampus (Fig. 3B).

Full-length or N-truncated $A \beta 40$ and $A \beta 42$ are two significant factors contributing to $A \beta$ aggregation, and the ratio of $\mathrm{A} \beta 40 / 42$ has a notable effect on the neurotoxicity of Ab fibrils, being associated with the onset of familial AD (24). ELISA assay revealed that there were significant differences in the soluble A $\beta$ level between the PBS-injected control group and the hAMMSC group. hAMMSC-transplanted mice exhibited 

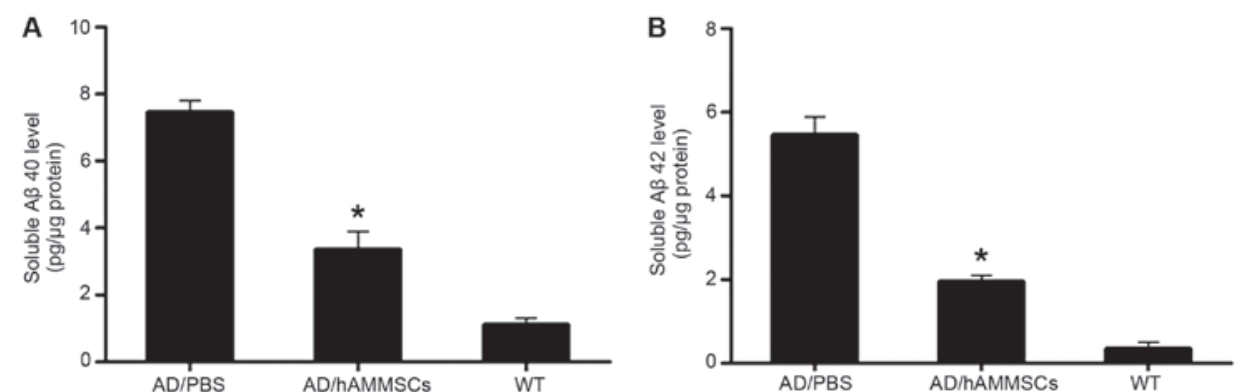

Figure 4. Enzyme-linked immunosorbent assay results of soluble amyloid- $\beta$ (A $\beta) 40$ and A $\beta 42$ levels in the (A) cortex and (B) hippocampus of Alzheimer's disease (AD) transgenic mice. Human amniotic membrane-derived mesenchymal stem cell (hAMMSC)-transplanted mice demonstrated a notable reduction in the soluble $\mathrm{A} \beta$ level compared with phosphate-buffered saline (PBS)-infused mice (" $\mathrm{P}<0.05)$. WT, negative control group.
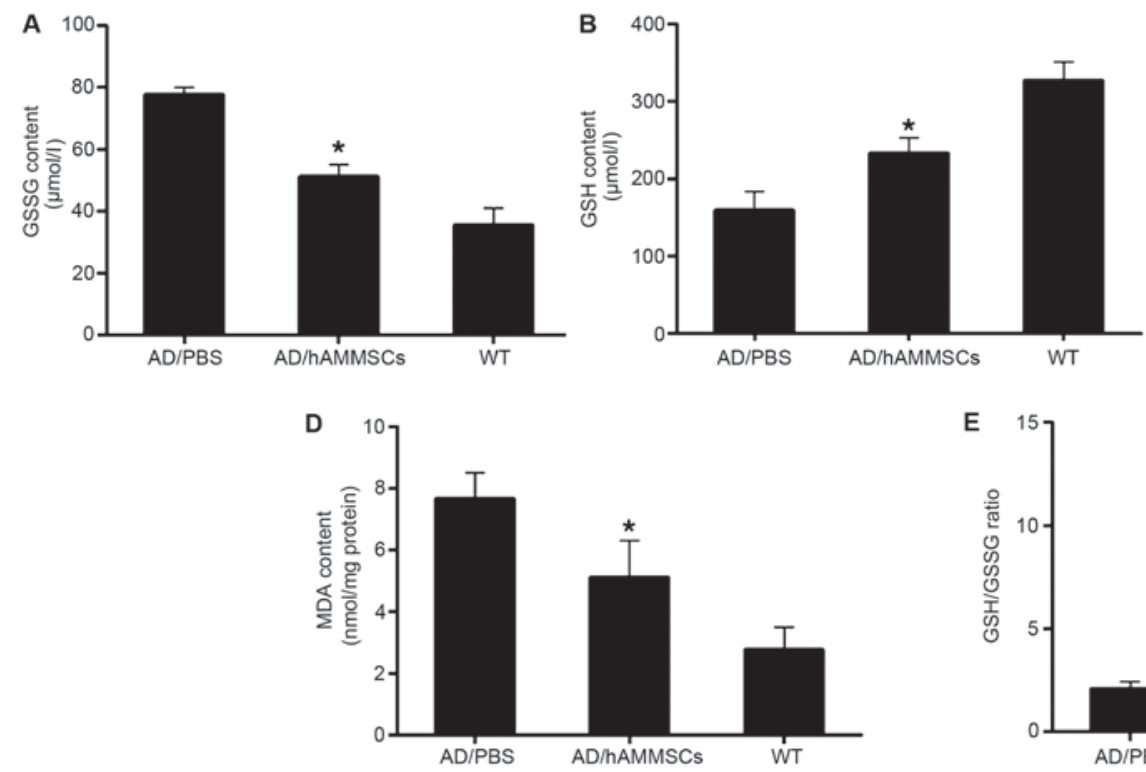
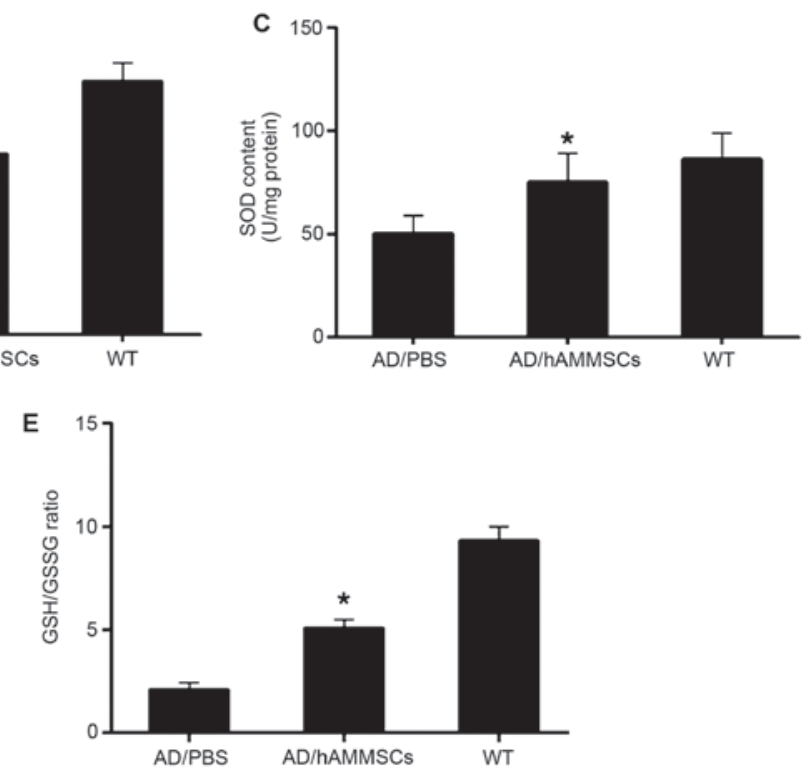

Figure 5. Human amniotic membrane-derived mesenchymal stem cells (hAMMSCs) reduced oxidative stress in Alzheimer's disease (AD) transgenic mice. The levels of (A) glutathione disulfide (GSSG), (B) glutathione (GSH), (C) the extent of lipid peroxidation malonaldehyde (MDA) and (D) the activity of antioxidant enzyme superoxide dismutase (SOD) were measured by assay kit spectrophotometrically. (E) The GSH/GSSG ratio was calculated. ${ }^{*} \mathrm{P}<0.05$ vs. phosphate-buffered saline (PBS)-treated control group. WT, negative control group.

a notably decreased A $\beta$ level compared with PBS-infused mice (Fig. 4A and B). Collectively, these results indicate that hAMMSC transplantation attenuates the deposition of $\mathrm{A} \beta$ in a transgenic mice model.

hAMMSCs reduce oxidative stress in AD transgenic mice. Oxidative stress was proposed as an essential factor contributing to $A \beta$ neurotoxicity, which occurs at the prophase of $A D$ prior to the onset of clinical and pathological symptoms (25). $\mathrm{A} \beta$ deposition in the brain parenchyma causes lipid peroxidation and protein oxidation, damaging the mitochondria and resulting in the loss of oxidative function of significant proteins in numerous pathways, including glucose metabolic proteins and death of neurons (26). Since hAMMSC transplantation attenuated the deposition of $A \beta$, we further investigated whether hAMMSCs could decrease oxidative stress in AD mice. GSH acts as a crucial cellular antioxidant against oxidative stress by reducing hydrogen peroxides and hydroperoxides in addition to protecting protein thiol groups against oxidation (27). GSH is converted into GSSG by GPx to detoxify peroxides, and the reaction could be converted back by glutathione reductase. It is considered that the ratio of GSH/GSSG reflects the intracellular antioxidant level. Following the transplantation of hAMMSCs in AD transgenic mice, the GSH level was increased significantly but the GSSG level was only slightly lowered in brain homogenates (Fig. 5A and B). The GSH/GSSG ratio in the hAMMSC group was significantly elevated compared with that of the PBS group (Fig. 5C).

As a vital antioxidant enzyme, SOD catalyzes superoxide radical anions to $\mathrm{H}_{2} \mathrm{O}_{2}$, inducing the oxidization of polyunsaturated fatty acids and lipid peroxidation (28). MDA is an end product of lipid peroxidation, which is toxic to neurons. hAMMSC treatment notably enhanced the SOD activity and diminished the MDA level in the brain of AD transgenic mice in contrast with the PBS control group (Fig. 5D and E).

\section{Discussion}

Studies on the therapeutic effect of MSCs on AD indicate that the transplantation of MSCs could improve cognitive decline 
in $\mathrm{AD}$ mice. In this study, our data revealed that amniotic membrane could be used as a powerful cellular source for the generation of stem cells. The differentiation potential and the number of human bone marrow-derived MSCs decreased during culture. Derived from the epiblast following fertilization, amniotic membrane has a number of advantages over bone marrow and embryos. Amniotic membrane cells express low levels of myosin heavy chain class I antigens (29). It is reported that amniotic membrane cells could be induced to neural cells in special conditions and discharge neurotransmitters, including acetylcholine, norepinephrine and dopamine (30). Multipotent MSCs have previously been isolated from various placental tissues. Moreover, hAMMSCs exhibit inducible angiogenic potential and may be useful in therapeutic strategy for vascular diseases (31). Our results indicated that the cultured hAMMSCs had powerful vitality at passage 4, which ensured the subsequent experimental requirements.

Before performing the water maze test, there was no statistical difference in the basic locomotor and anxiety-like behaviors observed in the three groups of this study (the normal control group, the PBS-injected group and the hAMMSC-injected group). The escape latency observed from the PBS-injected group was poor compared with that of the normal control group. However, the hAMMSC group demonstrated improved escape latency and was not significantly different to the normal group. The hAMMSC group demonstrated an improved performance in memory function compared with the PBS group. The amount of $A \beta$ plaque was decreased significantly as the spatial learning and memory function ameliorated following hAMMSC transplantation, which was not observed in the PBS group. Our findings provide evidence that the improved cognitive function may be caused by the decreased amount of $A \beta$ plaques.

It is considered that $A \beta(1-42)$ oligomer is a toxic species and is correlated with learning and memory in the brain of mice (32). Whether the total plaque burden correlates well with the phenotypic variability of AD has not yet been ascertained. However, the molecular and structural composition of $\mathrm{A} \beta$, including the ratio of $A \beta 40 / 42$, is responsible for neurotoxicity (24). Studies have reported that the $A \beta 40 / 42$ ratio has a great impact on neurotoxicity and is associated with the onset of familial AD (33). Our findings demonstrated that cognitive function improved significantly as the $A \beta$ level decreased. Intracerebroventricular transplantation of hAMMSCs increased acetylcholine concentration and the number of hippocampal cholinergic neurites in AbPP/PS1 transgenic AD mice (34). Following hAMMSC injection, the number of ED1-positive phagocytic microglial cells associated with $A \beta$ plaques was enhanced, the expression levels of proinflammatory cytokines were decreased, and those of anti-inflammatory cytokines were increased (35).

In the progression of $\mathrm{AD}, \mathrm{A} \beta$ induces cytotoxicity correlated with oxidative stress, ROS production and mitochondrial dysfunction (36). Natural antioxidants, including EGb 761 and curcumin, decrease the A $\beta$-induced ROS generation and neuronal apoptosis to protect neuron function (37). As major antioxidant enzymes, SOD and GSH-Px remove harmful peroxide metabolites and block lipid peroxidation chain reaction to prevent cell damage by free radicals (28). The SOD activity and the level of GSH and GSSG are indicators of oxidative stress, and the level of MDA represents lipid peroxidation. The present study revealed that the GSH level and the GSH/GSSG ratio were higher in the hAMMSC group than in the PBS group. The SOD activity and MDA level were improved significantly as the level of $A \beta$ decreased, but there was no such trend in the PBS group. This finding provides further evidence that the improvement of antioxidative function may be triggered by a reduction in the amount of amyloid plaques following hAMMSC transplantation.

In summary, our findings have demonstrated that hAMMSC transplantation into an AD transgenic mice model attenuates the oxidative stress supported by the increased level of antioxidative enzymes and the decreased level of lipid peroxidation product, which is correlated with low levels of $A \beta$. Consequently, intravenous injection of hAMMSCs elevated spatial learning ability and memory function in the AD mouse model by stimulating antioxidative function, indicating that hAMMSCs are useful in the prevention and treatment of AD.

\section{Acknowledgements}

This study was supported by The Second Youth Innovation Fund of the Affiliated Hospital of Zhengzhou University (grant no. 2011YN01008) and The College and University Major Scientific Research Program of Henan Educational Committee (grant no's. 15A310011 and 16A310008).

\section{References}

1. Caughey B and Lansbury PT: Protofibrils, pores, fibrils, and neurodegeneration: separating the responsible protein aggregates from the innocent bystanders. Annu Rev Neurosci 26: 267-298, 2003.

2. de la Monte SM and Wands JR: Molecular indices of oxidative stress and mitochondrial dysfunction occur early and often progress with severity of Alzheimer's disease. J Alzheimers Dis 9: 167-181, 2006.

3. Perry VH and Holmes C: Microglial priming in neurodegenerative disease. Nat Rev Neurol 10: 217-224, 2014.

4. Behl C, Davis JB, Lesley R and Schubert D: Hydrogen peroxide mediates amyloid beta protein toxicity. Cell 77: 817-827, 1994

5. Manczak M, Anekonda TS, Henson E, Park BS, Quinn J and Reddy PH: Mitochondria are a direct site of A beta accumulation in Alzheimer's disease neurons: implications for free radical generation and oxidative damage in disease progression. Hum Mol Genet 15: 1437-1449, 2006.

6. Apelt J, Bigl M, Wunderlich P and Schliebs R: Aging-related increase in oxidative stress correlates with developmental pattern of beta-secretase activity and beta-amyloid plaque formation in transgenic $\mathrm{Tg} 2576$ mice with Alzheimer-like pathology. Int J Dev Neurosci 22: 475-484, 2004.

7. De Felice FG, Velasco PT, Lambert MP, Viola K, Fernandez SJ, Ferreira ST and Klein WL: Abeta oligomers induce neuronal oxidative stress through an $\mathrm{N}$-methyl-D-aspartate receptor-dependent mechanism that is blocked by the Alzheimer drug memantine. J Biol Chem 282: 11590-11601, 2007.

8. Li F, Calingasan NY, Yu F, Mauck WM, Toidze M, Almeida CG Takahashi RH, Carlson GA, Flint Beal M, Lin MT and Gouras GK: Increased plaque burden in brains of APP mutant MnSOD heterozygous knockout mice. J Neurochem 89: 1308-1312, 2004.

9. Nishida Y, Yokota T, Takahashi T, Uchihara T, Jishage K and Mizusawa $\mathrm{H}$ : Deletion of vitamin $\mathrm{E}$ enhances phenotype of Alzheimer disease model mouse. Biochem Biophys Res Commun 350: 530-536, 2006.

10. Chen L, Na R, Gu M, Richardson A and Ran Q: Lipid peroxidation up-regulates BACE1 expression in vivo: a possible early event of amyloidogenesis in Alzheimer's disease. J Neurochem 107: 197-207, 2008 
11. Quiroz-Baez R, Rojas E and Arias C: Oxidative stress promotes JNK-dependent amyloidogenic processing of normally expressed human APP by differential modification of alpha-, beta- and gamma-secretase expression. Neurochem Int 55: 662-670, 2009.

12. Butterfield DA: The 2013 SFRBM discovery award: selected discoveries from the Butterfield laboratory of oxidative stress and its sequela in brain in cognitive disorders exemplified by Alzheimer disease and chemotherapy induced cognitive impairment. Free Radic Biol Med 74: 157-174, 2014.

13. Lindvall $\mathrm{O}$ and Kokaia Z: Stem cells in human neurodegenerative disorders - time for clinical translation? J Clin Invest 120: 29-40, 2010.

14. Lanza C, Morando S, Voci A, Canesi L, Principato MC, Serpero LD, Mancardi G, Uccelli A and Vergani L: Neuroprotective mesenchymal stem cells are endowed with a potent antioxidant effect in vivo. J Neurochem 110: 1674-1684, 2009.

15. Calió ML, Marinho DS, Ko GM, Ribeiro RR, Carbonel AF, Oyama LM, Ormanji M, Guirao TP, Calió PL, Reis LA, et al: Transplantation of bone marrow mesenchymal stem cells decreases oxidative stress, apoptosis, and hippocampal damage in brain of a spontaneous stroke model. Free Radic Biol Med 70 : $141-154,2014$.

16. Ko E, Lee KY and Hwang DS: Human umbilical cord bloodderived mesenchymal stem cells undergo cellular senescence in response to oxidative stress. Stem Cells Dev 21: 1877-1886, 2012

17. Tsuji H, Miyoshi S, Ikegami Y, Hida N, Asada H, Togashi I, Suzuki J, Satake M, Nakamizo H, Tanaka M, et al: Xenografted human amniotic membrane-derived mesenchymal stem cells are immunologically tolerated and transdifferentiated into cardiomyocytes. Circ Res 106: 1613-1623, 2010.

18. Dominici M, Le Blanc K, Mueller I, Slaper-Cortenbach I, Marini F, Krause D, Deans R, Keating A, Prockop Dj and Horwitz E: Minimal criteria for defining multipotent mesenchymal stromal cells. The International Society for Cellular Therapy position statement. Cytotherapy 8: 315-317, 2006.

19. Zhang J, Wu X, Qin C, Qi J, Ma S, Zhang H, Kong Q, Chen D, $\mathrm{Ba} \mathrm{D}$ and $\mathrm{He} \mathrm{W}$ : A novel recombinant adeno-associated virus vaccine reduces behavioral impairment and beta-amyloid plaques in a mouse model of Alzheimer's disease. Neurobiol Dis 14: 365-379, 2003.

20. Vorhees CV and Williams MT: Morris water maze: procedures for assessing spatial and related forms of learning and memory. Nat Protoc 1: 848-858, 2006.

21. Zhang W, Bai M, Xi Y, Hao J, Liu L, Mao N, Su C, Miao J and $\mathrm{Li} \mathrm{Z}$ : Early memory deficits precede plaque deposition in APPswe/PS1dE9 mice: involvement of oxidative stress and cholinergic dysfunction. Free Radic Biol Med 52: 1443-1452, 2012.

22. Dong HS, Li L, Song ZH, Tang J, Xu B, Zhai XW, Sun LL, Zhang P, Li ZB, Pan QJ, et al: Premeiotic fetal murine germ cells cultured in vitro form typical oocyte-like cells but do not progress through meiosis. Theriogenology 72: 219-231, 2009.

23. Hu D, Cao Y, He R, Han N, Liu Z, Miao L and Yin J: Schizandrin, an antioxidant lignan from Schisandra chinensis, ameliorates A 31 -42-induced memory impairment in mice. Oxid Med Cell Longev 2012: 721721, 2012.
24. Kuperstein I, Broersen K, Benilova I, Rozenski J, Jonckheere W, Debulpaep M, Vandersteen A, Segers-Nolten I, Van Der Werf K, Subramaniam V, et al: Neurotoxicity of Alzheimer's disease $A \beta$ peptides is induced by small changes in the $A \beta 42$ to A $\beta 40$ ratio. EMBO J 29: 3408-3420, 2010.

25. Onyango IG and Khan SM: Oxidative stress, mitochondrial dysfunction, and stress signaling in Alzheimer's disease. Curr Alzheimer Res 3: 339-349, 2006.

26. Behl C: Oxidative stress in Alzheimer's disease: implications for prevention and therapy. Subcell Biochem 38: 65-78, 2005.

27. Khan RA, Khan MR and Sahreen S: Protective effects of rutin against potassium bromate induced nephrotoxicity in rats. BMC Complement Altern Med 12: 204, 2012.

28. Chauhan V and Chauhan A: Oxidative stress in Alzheimer's disease. Pathophysiology 13: 195-208, 2006.

29. Sakuragawa N, Tohyama J and Yamamoto H: Immunostaining of human amniotic epithelial cells: possible use as a transgene carrier in gene therapy for inborn errors of metabolism. Cell Transplant 4: 343-346, 1995.

30. Kakishita K, Elwan MA, Nakao N, Itakura T and Sakuragawa N: Human amniotic epithelial cells produce dopamine and survive after implantation into the striatum of a rat model of Parkinson's disease: a potential source of donor for transplantation therapy. Exp Neurol 165: 27-34, 2000.

31. Alviano F, Fossati V, Marchionni C, Arpinati M, Bonsi L, Franchina M, Lanzoni G, Cantoni S, Cavallini C, Bianchi F, et al: Term amniotic membrane is a high throughput source for multipotent mesenchymal stem cells with the ability to differentiate into endothelial cells in vitro. BMC Dev Biol 7: 11, 2007.

32. Klein WL: Synaptotoxic amyloid- $\beta$ oligomers: a molecular basis for the cause, diagnosis, and treatment of Alzheimer's disease? J Alzheimers Dis (33 Suppl 1): S49-S65, 2013.

33. Kumar-Singh S, Theuns J, Van Broeck B, Pirici D, Vennekens K, Corsmit E, Cruts M, Dermaut B, Wang R and Van Broeckhoven C: Mean age-of-onset of familial alzheimer disease caused by presenilin mutations correlates with both increased Abeta42 and decreased Abeta40. Hum Mutat 27: 686-695, 2006

34. Xue S, Chen C, Dong W, Hui G, Liu T and Guo L: Therapeutic effects of human amniotic epithelial cell transplantation on double-transgenic mice co-expressing APPswe and PS1 $\triangle E 9$-deleted genes. Sci China Life Sci 55: 132-140, 2012.

35. Kim KS, Kim HS, Park JM, Kim HW, Park MK, Lee HS, Lim DS, Lee TH, Chopp M and Moon J: Long-term immunomodulatory effect of amniotic stem cells in an Alzheimer's disease model. Neurobiol Aging 34: 2408-2420, 2013.

36. Camilleri A, Zarb C, Caruana M, Ostermeier U, Ghio S, Högen T, Schmidt F, Giese A and Vassallo N: Mitochondrial membrane permeabilisation by amyloid aggregates and protection by polyphenols. Biochim Biophys Acta 1828: 2532-2543, 2013.

37. Zhao $\mathrm{Y}$ and Zhao B: Natural antioxidants in prevention and management of Alzheimer's disease. Front Biosci (Elite Ed) 4: 794-808, 2012 